\title{
Correlation and prediction of trunk fat mass with four anthropometric indices in Chinese males
}

\author{
Su-Mei Xiao ${ }^{1} \dagger$, Shu-Feng Lei ${ }^{1} \uparrow$, Xiang-Ding Chen ${ }^{1} \dagger$, Man-Yuan Liu ${ }^{1}$, Wei-Xia Jian ${ }^{1}$, Hong Xu ${ }^{1}$, \\ Li-Jun Tan ${ }^{1}$, Fei-Yan Deng ${ }^{1}$, Yan-Jun Yang ${ }^{1}$, Yan-Bo Wang ${ }^{1}$, Xiao Sun ${ }^{1}$, Cheng Jiang ${ }^{1}$, Yan-Fang Guo ${ }^{1}$, \\ Jing-Jing Guo ${ }^{1}$, Yuan-Neng Li ${ }^{1}$, Hui Jiang ${ }^{1}$, Xue-Zhen Zhu ${ }^{2}$ and Hong-Wen Deng ${ }^{1,3} *$ \\ ${ }^{1}$ Laboratory of Molecular and Statistical Genetics, College of Life Sciences, Hunan Normal University, Changsha, Hunan 410081, \\ P. R. China \\ ${ }^{2}$ The Key Laboratory of Biomedical Information Engineering of Ministry of Education and Institute of Molecular Genetics, School \\ of Life Science and Technology, Xi'an Jiaotong University, Xi'an 710049, P. R. China \\ ${ }^{3}$ Department of Orthopedic Surgery, School of Medicine, University of Missouri-Kansas City, 2411 Holmes Street, Kansas City, \\ MO 64108, USA
}

(Received 3 August 2005 - Revised 27 January 2006 - Accepted 23 March 2006)

\begin{abstract}
To increase our understanding of the relationships of trunk fat mass $\left(\mathrm{FM}_{\mathrm{trunk}}\right)$ and four anthropometric indices in Chinese males, 1090 males aged 20-40 years were randomly recruited from the city of Changsha, China. Waist circumference (WC) and hip circumference (HC) were measured using standardized equipment, and three other anthropometric indices of BMI, waist:hip ratio (WHR) and conicity index (CoI) were calculated using weight, height, $\mathrm{HC}$ and $\mathrm{WC}$. FM $\mathrm{FM}_{\text {trunk }}$ (in $\mathrm{kg}$ ) was measured using a Hologic QDR $4500 \mathrm{~W}$ dual-energy X-ray absorptiometry scanner. There was an increasing trend of $\mathrm{FM}_{\text {trunk }}, \% \mathrm{FM}_{\text {trunk }}$ (percentage of $\mathrm{FM}_{\text {trunk }}$ ) and BMI, WC, WHR, CoI in successively older age groups (e.g. the mean $\mathrm{FM}_{\text {trunk }}$ values were 4.63 (SD 2.58), 5.39 (SD 2.74), 5.93 (SD 2.82), 6.57 (SD 2.94) in four 5-year age groups, respectively). FM trunk and $\% \mathrm{FM}_{\text {trunk }}$ were significantly correlated with four anthropometric indices with the Pearson's correlation coefficients ranging from $0 \cdot 25$ to 0.86. Principal component analysis was performed to form three principal components that interpreted over $99.5 \%$ of the total variation of four related anthropometric indices in all age groups, with over $65 \%$ of the total variation accounted by principal component 1 . Multiple regression analyses showed that three principal components explained a greater variance $\left(R^{2} 70 \cdot 0-80 \cdot 1 \%\right)$ in $\mathrm{FM}_{\text {trunk }}$ than did $\mathrm{BMI}$ or WC alone $\left(R^{2} 57 \cdot 8-\right.$ 74.1\%). The present results suggest that there is an increasing trend of $\mathrm{FM}_{\text {trunk }}$ and four anthropometric indices in successively older age groups; that age has important effects on the relationships of $\mathrm{FM}_{\text {trunk }}$ and studied anthropometric indices; and that the accuracy of predicting $\mathrm{FM}_{\text {trunk }}$ using four anthropometric indices is higher than using BMI or WC alone.
\end{abstract}

Anthropometric index: Trunk fat mass: Percentage of trunk fat mass: Principal component analysis

The prevalence of obesity is increasing worldwide: there are about 250 million obese adults, with far larger numbers of overweight adults (James \& Ralph, 1999). The preferential accumulation of adipose tissue in the central region, i.e. trunk fat mass $\left(\mathrm{FM}_{\text {trunk }}\right)$, is clearly associated with increased risk of human chronic diseases, such as diabetes and CVD (Van Pelt et al. 2002; Pi-Sunyer, 2004), although the potential mechanisms remain to be elucidated fully. In addition, there are ethnic and sex-specific distributions of body fat mass. Compared with Caucasians, the Asian population accumulates central fat mass at lower body weight (McKeigue et al. 1992). Observations have shown that the risks of excess central fat mass emerge stronger and the hazards of even modest weight gain seem more drastic in the Asian population (James \& Ralph, 1999). Men have been shown to have higher risks of disease for a given weight than women, which may be attributed to the propensity of depositing fat mass centrally in men (Vague et al. 1985; Pi-Sunyer, 2004). Therefore, the measure of fat mass at trunk is of clinical significance in Chinese males to identify who is at risk of such diseases.

A number of techniques have been developed to allow an accurate estimation of body fat mass, such as dual-energy $\mathrm{X}$-ray absorptiometry (DXA). However, it is difficult to apply these complex techniques widely for clinical measurement of total or regional fat mass in developing countries, including China, because the measurement approaches depending on such technologies incur relatively high cost. On the other hand, the anthropometric indices, with their simple and cheap characteristics, continue to play an important role in assessing overall and regional fat mass in clinical practice. Dozens of studies have used several anthropometric indices, such as

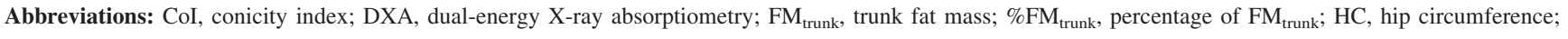
PC1, principal component 1; WC, waist circumference; WHR, waist:hip ratio.

* Corresponding author: Dr Hong-Wen Deng, Hunan Normal University, fax +867318872791, email hwdeng@hunnu.edu.cn

$\dagger$ These authors contributed equally to this article. 
BMI, waist circumference (WC), waist:hip ratio (WHR) and conicity index $(\mathrm{CoI})$, as predictors of central body fat mass (Taylor et al. 1998, 2000; Janssen et al. 2002; Brambilla et al. 2006), whereas the studies generally employed only one anthropometric index to predict fat mass, which may partially account for the current inconsistent results of the accuracy of the prediction, due to the potential confounders of adipose distribution.

To date, relatively few data on the correlations between anthropometric indices and truncal region fat mass measured by sophisticated methods, such as DXA, have been accumulated in the Chinese population. DXA is a safer and quicker method which typically has been used to assess bone mineral mass but also has been a valuable tool in assessing overall and regional body composition (Svendsen et al. 1993; Kohrt, 1995) than other technically complicated methods. However, to the best of our knowledge, there are no data on simultaneously employing the four anthropometric indices to assess trunk adipose tissue in either Chinese or Caucasians. Therefore, the current study was undertaken in Chinese males with three major aims: (1) to evaluate the effects of age on $\mathrm{FM}_{\text {trunk }}$ and anthropometric indices; (2) to investigate the correlations between $\mathrm{FM}_{\text {trunk }}$ and anthropometric indices; (3) to evaluate the ability of predicting $\mathrm{FM}_{\text {trunk }}$ using the four anthropometric indices (BMI, WC, WHR and $\mathrm{CoI}$ ) and to develop four age-specific equations to predict $\mathrm{FM}_{\text {trunk }}$ by the four anthropometric indices.

\section{Material and methods}

\section{Subjects}

The project was approved by the Research Administration Departments of Hunan Normal University. The subjects were from a large population that was randomly recruited, through the use of fliers and posters advertising in the surrounding communities of Hunan Normal University (located in the central south area of China), for genetic studies searching for genes underlying peak bone mass variation in the Chinese population. After the subjects signed informed consent documents, a questionnaire was given to obtain the subject's individual data including age, medical history, family history, physical activity, alcohol use, dietary habits and smoking history. We adopted the exclusion criteria detailed by Deng et al. (2002) to screen and recruit 'healthy' subjects. A total of 1090 healthy Chinese males, aged 20-40 years, were finally included in the study.

\section{Measurements}

Weight and height were measured using standardized equipment. BMI $\left(\mathrm{kg} / \mathrm{m}^{2}\right)$ was calculated as weight $(\mathrm{kg})$ divided by height squared $\left(\mathrm{m}^{2}\right)$. WC and $\mathrm{HC}$ were measured using an anthropometric tape over light clothing, with measurement of $\mathrm{WC}$ and $\mathrm{HC}$ at the minimum circumference between the iliac crest and the rib cage, and at the maximum protuberance of the buttocks. WHR was calculated as WC divided by HC. CoI was calculated using the following formula: $\mathrm{CoI}=\mathrm{WC} /$ $[0.109 \times \sqrt{ }($ weight/height) $]$ (WC and height in $\mathrm{m}$; weight in kg) (Valdez et al. 1993; Taylor et al. 2000). Fat mass, lean mass and bone mineral mass were measured by Hologic QDR 4500 W DXA scanner (Hologic Corp., Waltham, MA, USA). Body regions are distinguished using specific anatomic landmarks. The truncal region consists of the area bordered by a horizontal line below the chin, vertical borders lateral to the ribs and oblique lines passing through the femoral necks. The percentage of $\mathrm{FM}_{\text {trunk }}\left(\% \mathrm{FM}_{\text {trunk }}\right)$ was calculated as $\left[\mathrm{FM}_{\text {trunk }} /\right.$ $\left(\mathrm{FM}_{\text {trunk }}+\right.$ trunk lean mass + trunk bone mineral content $\left.)\right]$. The normal and standard DXA quality control measures and equipment checks were conducted following the manufacturer's recommendations before each testing session. The $\mathrm{CV}$ of $\mathrm{FM}_{\text {trunk }}$, obtained from thirty individuals repeatedly measured twice, of the DXA measurements was $0.99 \%$.

\section{Statistical analysis}

Statistical analyses were performed with the SAS package (SAS Institute Inc., Cary, NC, USA). To investigate the effects of age, we divided the individuals into four 5-year age groups (20-24 years, 25-29 years, 30-34 years and 35-39 years). Pearson's correlation coefficients were used to investigate the linear correlation of $\mathrm{FM}_{\text {trunk }}$ and $\% \mathrm{FM}_{\text {trunk }}$ with each anthropometric index. Because of the disturbance of the colinearity when simultaneously modelling four strongly correlated anthropometric indices (BMI, WC, WHR and CoI) in the multiple regression analysis, to avoid these confused effects, a principal component analysis was performed to form three principal components accounting for most of the variation of the four anthropometric indices, as well as eigenvalues of the matrix and eigenvectors. Subsequently, the three principal component values were calculated by eigenvalues of the matrix and eigenvectors (Green, 1978; Vapnik, 1998), and then they were used to estimate their regression coefficients and the proportion of the variance $\left(R^{2}\right)$ of $\mathrm{FM}_{\text {trunk }}$ predicted by these principal components by multiple regression analysis. Regression analyses were also conducted to determine whether the three principal components explained a greater variance $\left(R^{2}\right)$ of $\mathrm{FM}_{\text {trunk }}$ than did BMI or WC alone and also to investigate the correlation coefficients of the measured $\mathrm{FM}_{\text {trunk }}$ and the predicted $\mathrm{FM}_{\text {trunk }}$ by the three principal components and by BMI or WC alone. Finally, we developed four age-specific equations to predict $\mathrm{FM}_{\text {trunk }}$ by the measured values of four anthropometric indices. The equations were calculated as follows:

$$
\begin{aligned}
\text { The predicted } \mathrm{FM}_{\text {trunk }}(\mathrm{kg})= & \text { intercept }+\mathrm{RC}_{\mathrm{PC} 1} \\
& \times \mathrm{PC} 1\left(\mathrm{E}_{\mathrm{PC} 1 \mathrm{BMI}} \times \mathrm{S}_{\mathrm{BMI}}\right. \\
& +\mathrm{E}_{\mathrm{PC} 1 \mathrm{WC}} \times \mathrm{S}_{\mathrm{WC}}+\mathrm{E}_{\mathrm{PC} 1 \mathrm{WHR}} \\
& \left.\times \mathrm{S}_{\mathrm{WHR}}+\mathrm{E}_{\mathrm{PC} 1 \mathrm{CoI}} \times \mathrm{S}_{\mathrm{CoI}}\right) \\
& +\mathrm{RC}_{\mathrm{PC} 2} \times \mathrm{PC} 2\left(\mathrm{E}_{\mathrm{PC} 2 \mathrm{BMI}} \times \mathrm{S}_{\mathrm{BMI}}\right. \\
& +\mathrm{E}_{\mathrm{PC} 2 \mathrm{WC}} \times \mathrm{S}_{\mathrm{WC}}+\mathrm{E}_{\mathrm{PC} 2 \mathrm{WHR}} \\
& \left.\times \mathrm{S}_{\mathrm{WHR}}+\mathrm{E}_{\mathrm{PC} 2 \mathrm{CoI}} \times \mathrm{S}_{\mathrm{CoI}}\right) \\
& +\mathrm{RC}_{\mathrm{PC} 3} \times \mathrm{PC} 3\left(\mathrm{E}_{\mathrm{PC} 3 \mathrm{BMI}} \times \mathrm{S}_{\mathrm{BMI}}\right. \\
& +\mathrm{E}_{\mathrm{PC} 3 \mathrm{WC}} \times \mathrm{S}_{\mathrm{WC}}+\mathrm{E}_{\mathrm{PC} 3 \mathrm{WHR}} \\
& \left.\times \mathrm{S}_{\mathrm{WHR}}+\mathrm{E}_{\mathrm{PC} 3 \mathrm{CoI}} \times \mathrm{S}_{\mathrm{CoI}}\right)
\end{aligned}
$$


where $\mathrm{RC}_{\mathrm{PC} n}$ is the regression coefficient for the three principal components, respectively; $\mathrm{E}_{\mathrm{PC} n \mathrm{BMI}}, \mathrm{E}_{\mathrm{PC} n \mathrm{WC}}, \mathrm{E}_{\mathrm{PC} n \mathrm{WHR}}$ and $\mathrm{E}_{\mathrm{PC} n \mathrm{CoI}}$ are the corresponding eigenvectors of $\mathrm{BMI}$, WC, WHR and CoI for the three principal components; $\mathrm{S}_{\mathrm{BMI}}, \mathrm{S}_{\mathrm{WC}}, \mathrm{S}_{\mathrm{WHR}}$ and $\mathrm{S}_{\mathrm{CoI}}$ are the corresponding standard values [(measured value - mean measured value)/standard deviation of measured value] for each anthropometric index.

\section{Results}

Age was significantly correlated with $\mathrm{FM}_{\text {trunk }}, \% \mathrm{FM}_{\text {trunk }}$ and the four studied anthropometric indices in the whole group, but was not significantly associated with them in each 5 -year age group (data not shown). The subject characteristics for total and each of four groups are summarized in Table 1. There was an increasing trend of $\mathrm{FM}_{\text {trunk }}, \% \mathrm{FM}_{\text {trunk }}$, BMI, WC, WHR and CoI in successively older age groups (e.g. mean $\mathrm{FM}_{\text {trunk }}$ was 4.63 (SD 2.58), 5.39 (SD 2.74), 5.93 (SD 2.82) and 6.57 (SD 2.94) in the four 5-year age groups, respectively).

Correlations between $\mathrm{FM}_{\text {trunk }}$ and the four anthropometric indices were generally higher than those between $\% \mathrm{FM}_{\text {trunk }}$ and the studied anthropometric indices in each age group (Table 2). The higher correlations resulted in more accurate predictions, and thus the following analyses focused on the prediction of $\mathrm{FM}_{\text {trunk }}$ with the four anthropometric indices. $\mathrm{FM}_{\text {trunk }}$ and $\% \mathrm{FM}_{\text {trunk }}$ were significantly correlated with BMI, WC, WHR and CoI, with the correlation coefficients ranging from 0.25 to 0.86 . In each age group, the correlation coefficients of BMI and WC with $\mathrm{FM}_{\text {trunk }}$ were significantly higher than those of WHR or CoI with $\mathrm{FM}_{\text {trunk }}$ (e.g. the correlation coefficients between $\mathrm{FM}_{\text {trunk }}$ and BMI, WC, CoI and WHR in the 20-24 age group were 0.84, 0.81, 0.48 and $0 \cdot 26$, respectively).

As shown in Table 3, the three principal components interpreted over $99.5 \%$ of the total variation of four relative anthropometric indices by principal component analysis, with over $65 \%$ of the total variation accounted for by PC1. Regression analyses (Table 4) showed that the three principal components explained a greater variance $\left(R^{2} 70 \cdot 0-80 \cdot 1 \%\right)$ of $\mathrm{FM}_{\text {trunk }}$ than did BMI or WC alone $\left(R^{2} 57 \cdot 8-74 \cdot 1 \%\right)$ (e.g. in the $20-24$ age group, the proportions were $65.0,70.9$ and $75.6 \%$ by WC, $\mathrm{BMI}$ and the three principal components, respectively). Although the three principal components or BMI, WC, WHR and CoI were strongly correlated with $\mathrm{FM}_{\text {trunk }}$, approximately more than $20 \%$ of the variance in $\mathrm{FM}_{\text {trunk }}$ remained unexplained by them. Figure 1 intuitively illuminates the simple correlation coefficients between the measured $\mathrm{FM}_{\text {trunk }}$ and the predicted $\mathrm{FM}_{\text {trunk }}$ by the three principal components, single BMI or WC in regression analyses. Obviously, the correlations of the measured $\mathrm{FM}_{\text {trunk }}$ and the predicted $\mathrm{FM}_{\text {trunk }}$ by three principal components were higher than by BMI or WC alone, indicating that the three principal components predicted a more precise $\mathrm{FM}_{\text {trunk }}$ than did BMI or WC alone. We also developed four age-specific simple equations to predict $\mathrm{FM}_{\text {trunk }}$ using measured values of the four anthropometric indices (Table 5), which were detailed in the statistical analysis. Then, to investigate the external validation of predicting $\mathrm{FM}_{\text {trunk }}$, we determined the equations to predict $\mathrm{FM}_{\text {trunk }}$ in half of the randomly collected subjects and tested the prediction equations in the other half. The prediction equations in half of the randomly collected samples were very similar to those in the whole samples (data not shown), and then the predicted $\mathrm{FM}_{\text {trunk }}$ using these equations in the other half were highly correlated with the measured $\mathrm{FM}_{\text {trunk }}(r$ 0.71-0.89).

\section{Discussion}

The major observation of the present study is that, independent of age, the use of BMI, WC, WHR and CoI in combination is better than using them alone for the prediction of $\mathrm{FM}_{\text {trunk }}$ in Chinese males. The present study also confirms the finding that age has a significant influence on the truncal region fat mass and four anthropometric indices, all of which increase in ageing groups. The central adipose tissue was a widely used predictor of health risk. Thus, the results of the present study may imply the importance and a more accurate pattern of incorporating these four anthropometric indices into routine clinical practice.

Table 1. Basic statistical characteristics of the studied sample of Chinese males*

(Mean values and standard deviations)

\begin{tabular}{|c|c|c|c|c|c|c|c|c|c|c|}
\hline & \multicolumn{8}{|c|}{ Age group (years) } & & \\
\hline & \multicolumn{2}{|c|}{$20-24(n 415)$} & \multicolumn{2}{|c|}{$25-29(n 472)$} & \multicolumn{2}{|c|}{$30-34(n$ 159) } & \multicolumn{2}{|c|}{$35-39(n 44)$} & \multicolumn{2}{|c|}{ Total $(n 1090)$} \\
\hline & Mean & SD & Mean & SD & Mean & SD & Mean & SD & Mean & SD \\
\hline Age (years) & $23 \cdot 7$ & 1.05 & $26 \cdot 9$ & 1.44 & $32 \cdot 0$ & 1.41 & $37 \cdot 3$ & 1.60 & $27 \cdot 2$ & $4 \cdot 17$ \\
\hline Height (m) & $1 \cdot 70$ & 0.05 & 1.69 & 0.05 & 1.68 & 0.05 & 1.68 & 0.06 & 1.69 & 0.05 \\
\hline Weight (kg) & $61 \cdot 3$ & $8 \cdot 29$ & $62 \cdot 8$ & 8.50 & 63.5 & $8 \cdot 13$ & $64 \cdot 8$ & $8 \cdot 36$ & $62 \cdot 6$ & $8 \cdot 58$ \\
\hline BMI $\left(\mathrm{kg} / \mathrm{m}^{2}\right)$ & $21 \cdot 2$ & 2.57 & 21.9 & $2 \cdot 71$ & $22 \cdot 4$ & $2 \cdot 63$ & $23 \cdot 0$ & 2.64 & $21 \cdot 8$ & 2.73 \\
\hline WC $(\mathrm{cm})$ & $74 \cdot 2$ & 7.59 & $76 \cdot 7$ & $7 \cdot 41$ & $78 \cdot 7$ & 7.54 & 79.9 & $7 \cdot 76$ & $76 \cdot 3$ & 7.85 \\
\hline $\mathrm{HC}(\mathrm{cm})$ & $90 \cdot 7$ & $6 \cdot 77$ & $92 \cdot 1$ & 5.93 & $93 \cdot 1$ & $7 \cdot 47$ & $93 \cdot 3$ & $5 \cdot 52$ & 91.8 & 6.56 \\
\hline WHR & 0.82 & 0.06 & 0.83 & 0.07 & 0.85 & 0.07 & 0.86 & 0.06 & 0.83 & 0.07 \\
\hline Col & $1 \cdot 14$ & 0.07 & $1 \cdot 16$ & 0.07 & $1 \cdot 18$ & 0.07 & $1 \cdot 18$ & 0.07 & $1 \cdot 15$ & 0.07 \\
\hline $\mathrm{FM}_{\text {trunk }}(\mathrm{kg})$ & $4 \cdot 63$ & 2.58 & $5 \cdot 39$ & $2 \cdot 74$ & 5.93 & $2 \cdot 82$ & 6.57 & 2.94 & $5 \cdot 28$ & 2.79 \\
\hline$\% \mathrm{FM}_{\text {trunk }}$ & $15 \cdot 72$ & $6 \cdot 28$ & $17 \cdot 69$ & $6 \cdot 65$ & $19 \cdot 12$ & 7.03 & $20 \cdot 58$ & $7 \cdot 21$ & $17 \cdot 37$ & $6 \cdot 78$ \\
\hline
\end{tabular}

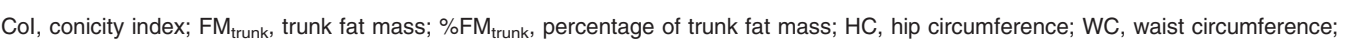
WHR, waist:hip ratio.

${ }^{*}$ For details of procedures, see p. 950. 
Table 2. Correlation coefficients of trunk fat mass $\left(\mathrm{FM}_{\text {trunk }}\right)$ and percentage of trunk fat mass (\%FM $\left.\mathrm{Frunk}_{\text {trun }}\right)$ with anthropometric indices

\begin{tabular}{lllll}
\hline & \multicolumn{4}{c}{ Age group (years) } \\
\cline { 2 - 5 } & $20-24$ & $25-29$ & $30-34$ & $35-39$ \\
\hline FM $_{\text {trunk }}(\mathrm{kg})$ & & & & \\
BMI & 0.84 & 0.86 & 0.79 & 0.85 \\
WC & 0.81 & 0.79 & 0.76 & 0.84 \\
WHR & 0.26 & 0.41 & 0.31 & 0.74 \\
Col & 0.48 & 0.40 & 0.42 & 0.62 \\
\%FM & & & & \\
BMl & 0.76 & 0.78 & 0.70 & 0.72 \\
WC & 0.74 & 0.72 & 0.70 & 0.73 \\
WHR & 0.25 & 0.39 & 0.32 & 0.71 \\
Col & 0.47 & 0.40 & 0.42 & 0.61 \\
\end{tabular}

Col, conicity index; WC, waist circumference; WHR, waist:hip ratio.

Central fat mass was demonstrated to be strongly related with many chronic diseases (Folsom et al. 1990; Rexrode et al. 1998; Van Pelt et al. 2002), and in routine clinical practice, the inexpensive and convenient anthropometric index was commonly used for assessing central adipose tissue, especially in developing countries. However, compared with Caucasians, few data on the relationships of anthropometric indices with fat mass in the truncal region have been reported in the Chinese population. The apparent differences in energy expenditure and body build among various ethnic groups may lead to ethnic-specific relationships (Deurenberg et al. 1998; Duncan et al. 2004). Additionally, the higher incidence of some diseases, such as $\mathrm{CHD}$, in men compared to women, may partially result from the more central distribution of fat mass in men (Freedman et al. 1990; Larsson et al. 1992; Pi-Sunyer, 2004). Therefore, to increase our understanding of the ethnic-specific correlation and prediction of $\mathrm{FM}_{\text {trunk }}$ with four anthropometric indices, we conducted the present study in a large cohort of Chinese males with ages ranging from 20 to 40 years.
Consistent with previous studies (Shimokata et al. 1989; Lemieux et al. 1995; Zamboni et al. 1997), the present results showed a progressive trend toward increasing central fat mass deposition with ageing, which gives support to the earlier finding that age had an effect on upper-body fat mass in males (Horber et al. 1997). It may be partially credited to blunted growth hormone and testosterone secretion in old men (Corpas et al. 1993; Bjorntorp, 1996; Johannsson et al. 1997; Harman \& Blackman, 2004). Johannsson et al. (1997) found that growth hormone treatment in adult men with abdominal obesity had favourable effects on abdominal fat mass and several obesity-related diseases. Declining physical activity with ageing may also enhance a more central shape (Mitchell et al. 2003; Parsons et al. 2005). Thus, to try to decrease the disturbance of age on the estimation of relationships between four anthropometric indices and $\mathrm{FM}_{\text {trunk }}$, it was appropriate to divide our sample into four 5-year age groups, because age was significantly correlated with $\mathrm{FM}_{\text {trunk }}$ and four anthropometric indices in all samples, but was not associated with them in each divided age group.

We have confirmed that the four anthropometric indices were highly correlated with $\mathrm{FM}_{\text {trunk }}$ and $\% \mathrm{FM}_{\text {trunk }}$, and BMI and WC were better predictors of $\mathrm{FM}_{\text {trunk }}$ than were WHR and CoI (Lean et al. 1995; Taylor et al. 2000; Snijder et al. 2004). However, more importantly, the present results indicated that the three principal components from four anthropometric indices assessed $\mathrm{FM}_{\text {trunk }}$ more accurately than did BMI, WC, WHR and CoI alone, explaining at least an additional

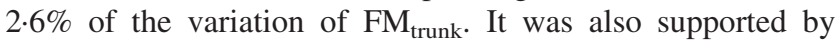
the simple correlation coefficients between the measured $\mathrm{FM}_{\text {trunk }}$ and the predicted $\mathrm{FM}_{\text {trunk }}$ by the three principal components, which were higher than those between the measured $\mathrm{FM}_{\text {trunk }}$ and the predicted $\mathrm{FM}_{\text {trunk }}$ by BMI or WC alone (Fig. 1). In past years, numerous studies have been striving for the accuracy of a single anthropometric index for estimating central fat mass, but the results have been largely inconsistent among the studies (Ross et al. 1994; Taylor et al. 1998, 2000; Kamel et al. 1999, 2000; Lindsay et al. 2001).

Table 3. Eigenvalues of the correlation matrix and eigenvectors in the principal component analysis for four anthropometric indices

\begin{tabular}{|c|c|c|c|c|c|c|}
\hline \multirow[b]{2}{*}{ Age group (years) } & \multicolumn{2}{|c|}{ Eigenvalues of the matrix } & \multicolumn{4}{|c|}{ Eigenvector } \\
\hline & Eigenvalue & Proportion & BMI & WC & WHR & Col \\
\hline \multicolumn{7}{|l|}{$20-24$} \\
\hline PC1 & $2 \cdot 602$ & 0.651 & 0.478 & 0.603 & 0.374 & 0.518 \\
\hline PC2 & 0.813 & 0.203 & -0.561 & -0.212 & 0.773 & 0.206 \\
\hline PC3 & 0.570 & 0.143 & 0.507 & -0.135 & 0.512 & -0.680 \\
\hline \multicolumn{7}{|l|}{$25-29$} \\
\hline PC1 & $2 \cdot 898$ & 0.728 & 0.418 & 0.567 & 0.498 & 0.506 \\
\hline PC2 & 0.849 & 0.212 & 0.755 & 0.216 & -0.410 & -0.464 \\
\hline PC3 & $0 \cdot 240$ & 0.060 & 0.159 & -0.294 & 0.763 & -0.553 \\
\hline \multicolumn{7}{|l|}{$30-34$} \\
\hline PC1 & $2 \cdot 796$ & 0.699 & 0.408 & 0.577 & 0.480 & 0.519 \\
\hline PC2 & 0.862 & $0 \cdot 215$ & 0.773 & 0.192 & -0.443 & -0.411 \\
\hline PC3 & 0.326 & 0.082 & 0.219 & -0.297 & 0.756 & -0.541 \\
\hline \multicolumn{7}{|l|}{$35-39$} \\
\hline PC1 & $3 \cdot 139$ & 0.785 & 0.466 & 0.552 & 0.495 & 0.483 \\
\hline PC2 & 0.546 & 0.136 & 0.755 & 0.068 & -0.173 & -0.630 \\
\hline PC3 & 0.297 & 0.074 & -0.108 & -0.325 & 0.851 & -0.398 \\
\hline
\end{tabular}

Col, conicity index; PC1, PC2, PC3, principal components derived from the four anthropometric indices by principal component analysis; WC, waist circumference; WHR, waist:hip ratio. 
Table 4. The $R^{2 *}$ and standard error of estimation (SEE) of the three principal components (PC), BMl or waist circumference (WC) and the regression coefficients of the PC

\begin{tabular}{lcccc}
\hline & \multicolumn{4}{c}{ Age group (years) } \\
\cline { 2 - 5 } & $20-24$ & $25-29$ & $30-34$ & $35-39$ \\
\hline Variations & & & & \\
$R^{2}$ (PC) & 75.6 & 76.7 & 70.0 & 80.1 \\
SEE (PC) & 1.27 & 1.32 & 1.57 & 1.31 \\
$R^{2}$ (BMI) & 70.9 & 74.1 & 61.9 & 71.5 \\
SEE (BMI) & 1.40 & 1.40 & 1.75 & 1.52 \\
$R^{2}$ (WC) & 65.0 & 62.8 & 57.8 & 71.1 \\
SEE (WC) & 1.51 & 1.67 & 1.83 & 1.53 \\
Regression coefficients & & & \\
PC1 & 1.219 & 1.150 & 1.149 & 1.431 \\
PC2 & -1.093 & 1.515 & 1.474 & 0.960 \\
PC3 & 0.550 & -0.105 & -0.380 & 0.198 \\
Intercept & 4.60 & 5.41 & 5.91 & 6.57 \\
\hline
\end{tabular}

${ }^{*} R^{2}$ is the percentage of the variance of trunk fat mass explained by the three PC, BMI and WC

WC is a commonly and widely used tool for central adipose tissue assessment (Taylor et al. 1998, 2000; Snijder et al. 2004). However, the use of WC as the predictor of central fat mass has been criticized (Ross et al. 1994; Kamel et al. 2000) for the relatively low correlation coefficients between WC and central fat mass. Adipose distribution may partially disturb the accuracy of assessment as anatomic adipose distribution in the central region has been demonstrated to be different among individuals with differential BMI (Ross et al. 1994; Han et al. 1997; Kamel et al. 2000). Thus there are limitations in only using one anthropometric index to evaluate regional fat mass. In Janssen et al. 2002, demonstrated that the combined use of WC and BMI substantially increased the variance explained in abdominal subcutaneous and visceral fat mass than did either variable alone. Their results support our belief that it may be more significant and accurate to evaluate fat mass in the truncal region using combined anthropometric indices. BMI, WC, WHR and CoI were all useful and accurate tools for assessing central adipose tissue (Taylor et al. 1998, 2000; Janssen et al. 2002; Brambilla et al. 2006). However, as those indices were highly related, they cannot simply be involved in multiple regression analysis to predict $\mathrm{FM}_{\text {trunk }}$. A principal component analysis was adopted in the present study to attempt to extract useful information from these four related indices. To the best of our knowledge, the present study is the first effort to use four anthropometric indices simultaneously to predict $\mathrm{FM}_{\text {trunk }}$ in Chinese adult males with age varying from 20 to 40 years.

With the aim of predicting FM $_{\text {trunk }}$ with a simple method, in the present study we developed four age-specific equations using the measured values of four anthropometric indices which have practical significance for routine clinical assessment in Chinese males. The validation of predicting $\mathrm{FM}_{\text {trunk }}$ is very high. The correlation coefficients between the measured $\mathrm{FM}_{\text {trunk }}$ and predicted $\mathrm{FM}_{\text {trunk }}$ by the three principal components using multiple regression analysis were high, ranging from 0.83 to 0.88 (Fig. 1). Although predictive equations have been developed and proposed for estimating central fat mass by combining anthropometric indices with DXA data in Caucasians (Jensen et al. 1995; Bertin et al. 2000), several studies have reported the limitations when the generalized formulas based on Caucasians were used to estimate the body composition of non-white populations (Vickery et al. 1988; Jakicic et al. 1998). Furthermore, the assessment of adipose tissue with measurement of anthropometric indices is much cheaper and technically easier than using DXA, computed tomography or magnetic resonance imaging. Therefore, it is of very important clinical implication to develop ethnic-specific equations for accurately assessing central fat mass using simple and costless anthropometric indices, especially in developing countries like China. This is the primary motive for performing the present study in the Chinese population.

However, the present study has some limitations. First, although DXA as a three-component model is becoming increasingly popular for the measurement of soft tissue composition as well as bone mineral mass, it cannot distinguish between visceral and subcutaneous adipose tissue and is less accurate compared with computed tomography or magnetic resonance imaging. But research has illustrated strong correlations between the fat mass at trunk measured by DXA and abdominal fat mass measured with computed tomography or

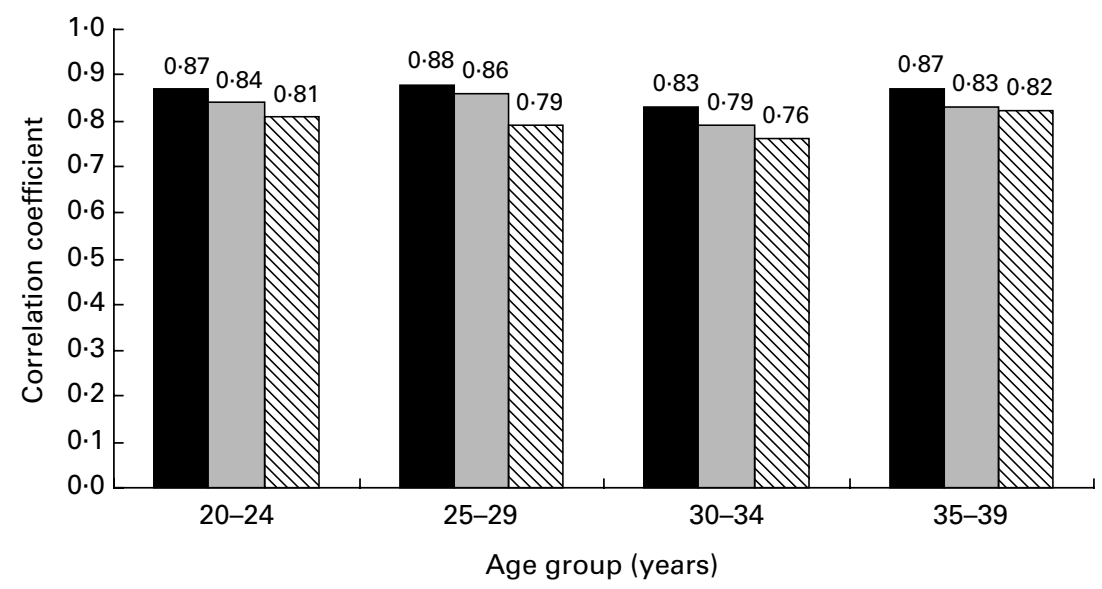

Fig. 1. Simple correlation coefficients, using regression analysis, between trunk fat mass $\left(\mathrm{FM}_{\text {trunk }}\right)$ and the predicted $F M_{\text {trunk }}$ by the three principal components $(\square)$, BMI ( $\square$ ) and waist circumference ( $\nabla)$. For details of procedures, see pp. 950-951. 
Table 5. Predicted trunk fat mass $\left(\mathrm{FM}_{\text {trunk }}\right)^{\star}$ calculated from the measured values of four anthropometric indices using principle component analysis

\begin{tabular}{|c|c|}
\hline Age group (years) & Predicted equation \\
\hline $20-24$ & Predicted $\mathrm{FM}_{\text {trunk }}(\mathrm{kg})=0.5738 \times \mathrm{BMI}+0.1176 \times \mathrm{WC}(\mathrm{cm})-1.7891 \times \mathrm{WHR}+0.4645 \times \mathrm{Col}-15.3484$ \\
\hline $25-29$ & Predicted $\mathrm{FM}_{\text {trunk }}(\mathrm{kg})=0.5934 \times \mathrm{BMI}+0.1364 \times \mathrm{WC}(\mathrm{cm})-1.8377 \times$ WHR $-0.8922 \times \mathrm{Col}-15.4855$ \\
\hline $30-34$ & Predicted $\mathrm{FM}_{\text {trunk }}(\mathrm{kg})=0.5802 \times \mathrm{BMI}+0.1403 \times \mathrm{WC}(\mathrm{cm})-5.5438 \times \mathrm{WHR}+2.7996 \times \mathrm{Col}-16.7229$ \\
\hline 35-39 & Predicted $\mathrm{FM}_{\text {trunk }}(\mathrm{kg})=0.5190 \times \mathrm{BMI}+0.1018 \times \mathrm{WC}(\mathrm{cm})+13.2577 \times \mathrm{WHR}+0.1302 \times \mathrm{Col}-25.0608$ \\
\hline
\end{tabular}

Col, conicity index; WC, waist circumference; WHR, waist:hip ratio.

${ }^{*}$ For the equation for predicted FM $_{\text {trunk }}$, see p. 950.

magnetic resonance imaging (Treuth et al. 1995; Goran et al. 1998; Glickman et al. 2004). Second, the present results from a healthy population with normal body weight might be inappropriate for obese populations or other patients with chronic diseases and conditions. But, central fat mass is an undeniable necessity for accessing disease risk in non-obese populations as well. Goodpaster et al. (2005) demonstrated that apart from general fat mass, the abdominal adipose tissue was independently associated with the metabolic syndrome in men and women, particularly among those of normal body weight. Third, the subjects were aged between 20 and 40 years. Therefore, it may not be possible to generalize the results of the present study to older or younger Chinese males. Fourth, the small number of men in the 35-39 age group (only fortyfour subjects) may easily result in randomized bias. Therefore, an expanded sample in this age group should be recruited in a further study to form more confident results.

In conclusion, the present study explored the complex relationships between four anthropometric indices and $\mathrm{FM}_{\text {trunk }}$ in a very large sample of Chinese males with ages varying from 20 to 40 years. The results obtained added to our understanding of the relationships of anthropometric indices and fat mass in the trunk region, as well as the effects of age on them.

\section{Acknowledgements}

We thank the anonymous reviewers for their comments on improving this paper. The study was partially supported by a key project grant (30230210), a general grant (30470534) from the National Science Foundation of China, three projects from the Scientific Research Fund of Hunan Provincial Education Department (02A027, 03C226, 04B039), and a grant from the Natural Science Foundation of Hunan Province (04JJ1004). H. W. D. was partially supported by grants from the Health Future Foundation of USA, and grants from the National Health Institute (K01 AR02170-01A2, R01 GM60402 and 5R01 AR050496-02).

\section{References}

Bertin E, Marcus C, Ruiz JC, Eschard JP \& Leutenegger M (2000) Measurement of visceral adipose tissue by DXA combined with anthropometry in obese humans. Int J Obes Relat Metab Disord 24, 263-270.

Bjorntorp P (1996) The regulation of adipose tissue distribution in humans. Int J Obes Relat Metab Disord 20, 291-302.

Brambilla P, Bedogni G, Moreno LA, Goran MI, Gutin B, Fox KR, Peters DM, Barbeau P, Simone MD \& Pietrobelli A (2006) Crossvalidation of anthropometry against magnetic resonance imaging for the assessment of visceral and subcutaneous adipose tissue in children. Int J Obes (Lond) 30, 23-30.

Corpas E, Harman SM \& Blackman MR (1993) Human growth hormone and human aging. Endocr Rev 14, 20-39.

Deng HW, Shen H, Xu FH, Deng HY, Conway T, Zhang HT \& Recker RR (2002) Tests of linkage and/or association of genes for vitamin D receptor, osteocalcin, and parathyroid hormone with bone mineral density. J Bone Miner Res 17, 678-686.

Deurenberg P, Yap M \& van Staveren WA (1998) Body mass index and percent body fat: a meta analysis among different ethnic groups. Int J Obes Relat Metab Disord 22, 1164-1171.

Duncan E, Schofield G, Duncan S, Kolt G \& Rush E (2004) Ethnicity and body fatness in New Zealanders. N Z Med J 117, U913.

Folsom AR, Prineas RJ, Kaye SA \& Munger RG (1990) Incidence of hypertension and stroke in relation to body fat distribution and other risk factors in older women. Stroke 21, 701-706.

Freedman DS, Jacobsen SJ, Barboriak JJ, Sobocinski KA, Anderson AJ, Kissebah AH, Sasse EA \& Gruchow HW (1990) Body fat distribution and male/female differences in lipids and lipoproteins. Circulation 81, 1498-1506.

Glickman SG, Marn CS, Supiano MA \& Dengel DR (2004) Validity and reliability of dual-energy X-ray absorptiometry for the assessment of abdominal adiposity. J Appl Physiol 97, 509-514.

Goodpaster BH, Krishnaswami S, Harris TB, Katsiaras A, Kritchevsky SB, Simonsick EM, Nevitt M, Holvoet P \& Newman AB (2005) Obesity, regional body fat distribution, and the metabolic syndrome in older men and women. Arch Intern Med 165, 777-783.

Goran MI, Gower BA, Treuth M \& Nagy TR (1998) Prediction of intra-abdominal and subcutaneous abdominal adipose tissue in healthy pre-pubertal children. Int J Obes Relat 22, 549-558.

Green PE (1978) Analyzing Multivariate Data. Hinsdale, IL: The Dryden Press.

Han TS, Kelly IE, Walsh K, Greene RM \& Lean ME (1997) Relationship between volumes and areas from single transverse scans of intra-abdominal fat measured by magnetic resonance imaging. Int J Obes Relat Metab Disord 21, 1161-1166.

Harman SM \& Blackman MR (2004) Use of growth hormone for prevention or treatment of effects of aging. J Gerontol A Biol Sci Med Sci 59, 652-658.

Horber FF, Gruber B, Thomi F, Jensen EX \& Jaeger P (1997) Effect of sex and age on bone mass, body composition and fuel metabolism in humans. Nutrition 13, 524-534.

Jakicic JM, Wing RR \& Lang W (1998) Bioelectrical impedance analysis to assess body composition in obese adult women: effect of ethnicity. Int J Obes Relat Metab Disord 22, 243-249.

James WPT \& Ralph A (1999) New understanding in obesity research. Proc Nutr Soc 58, 385-393.

Janssen I, Heymsfield SB, Allison DB, Kotler DP \& Ross R (2002) Body mass index and waist circumference independently contribute to the prediction of nonabdominal, abdominal subcutaneous and visceral fat. Am J Clin Nutr 75, 683-688.

Jensen MD, Kanaley JA, Reed JE \& Sheedy PF (1995) Measurement of abdominal and visceral fat with computed tomography and dualenergy x-ray absorptiometry. Am J Clin Nutr 61, 274-278. 
Johannsson G, Marin P, Lonn L, Ottosson M, Stenlof K, Bjorntorp P, Sjostrom L \& Bengtsson BA (1997) Growth hormone treatment of abdominally obese men reduces abdominal fat mass, improves glucose and lipoprotein metabolism, and reduces diastolic blood pressure. J Clin Endocrinol Metab 82, 727-734.

Kamel EG, McNeill G, Han TS, Smith FW, Avenell A, Davidson L \& Tothill P (1999) Measurement of abdominal fat by magnetic resonance imaging, dual-energy X-ray absorptiometry and anthropometry in non-obese men and women. Int J Obes Relat Metab Disord 23, 686-692.

Kamel EG, McNeill G \& Van Wijk MC (2000) Usefulness of anthropometry and DXA in predicting intra-abdominal fat in obese men and women. Obes Res 8, 36-42.

Kohrt WM (1995) Body composition by DXA: tried and true? Med Sci Sports Exerc 27, 1349-1353.

Larsson B, Bengtsson C, Bjorntorp P, Lapidus L, Sjostrom L, Svardsudd K, Tibblin G, Wedel H, Welin L \& Wilhelmsen L (1992) Is abdominal body fat distribution a major explanation for the sex difference in the incidence of myocardial infarction? The study of men born in 1913 and the study of women. Goteborg, Sweden. Am J Epidemiol 135, 266-273.

Lean ME, Han TS \& Morrison CE (1995) Waist circumference as a measure for indicating need for weight management. $\mathrm{Br}$ Med $\mathrm{J} \mathbf{1 5}$, $158-161$.

Lemieux S, Prud'homme D, Moorjani S, Tremblay A, Bouchard C, Lupien PJ \& Despres JP (1995) Do elevated levels of abdominal visceral adipose tissue contribute to age-related differences in plasma lipoprotein concentrations in men? Atherosclerosis 118, $155-164$.

Lindsay RS, Hanson RL, Roumain J, Ravussin E, Knowler WC \& Tataranni PA (2001) Body mass index as a measure of adiposity in children and adolescents: relationship to adiposity by dual energy $\mathrm{x}$-ray absorptiometry and to cardiovascular risk factors. J Clin Endocrinol Metab 86, 4061-4067.

McKeigue PM, Pierpoint T, Ferrie JE \& Marmot MG (1992) Relationship of glucose intolerance and hyperinsulinemia to body fat pattern in South Asians and Europeans. Diabetologia 35, $785-791$.

Mitchell D, Haan MN, Steinberg FM \& Visser M (2003) Body composition in the elderly: the influence of nutritional factors and physical activity. J Nutr Health Aging 7, 130-139.

Parsons TJ, Power C \& Manor O (2005) Physical activity, television viewing and body mass index: a cross-sectional analysis from childhood to adulthood in the 1958 British cohort. Int $J$ Obes (Lond) 29, 1212-1221.

Pi-Sunyer FX (2004) The epidemiology of central fat distribution in relation to disease. Nutr Rev 62, S120-S126.

Rexrode K, Carey V, Hennekens C, Walters EE, Colditz GA, Stampfer MJ, Willett WC \& Manson JE (1998) Abdominal adiposity and coronary heart disease in women. JAMA 280, 1843-1848.
Ross R, Shaw KD, Rissanen J, Martel Y, de Guise J \& Avruch L (1994) Sex differences in lean and adipose tissue distribution by magnetic resonance imaging: anthropometric relationships. Am J Clin Nutr 59, 1277-1285.

Shimokata H, Tobin JD, Muller DC, Elahi D, Coon PJ \& Andres R (1989) Studies in the distribution of body fat: I. Effects of age, sex and obesity. J Gerontol 44, M66-73.

Snijder MB, Dekker JM, Visser M, Bouter LM, Stehouwer CD, Yudkin JS, Heine RJ, Nijpels G, Seidell JC \& Hoorn Study (2004) Trunk fat and leg fat have independent and opposite association with fasting and postload glucose levels. Diebetes Care 27, $372-377$.

Svendsen OL, Hassager C, Bergmann I \& Christiansen C (1993) Measurement of abdominal and intra-abdominal fat in postmenopausal women by dual energy X-ray absorptiometry and anthropometry: comparison with computerized tomography. Int $J$ Obes Relat Metab Disord 17, 45-51.

Taylor RW, Jones IE, Williams SM \& Goulding A (2000) Evaluation of waist circumference, waist-to-hip ratio, and the conicity index as screening tools for high trunk fat mass, as measured by dual-energy X-ray absorptiometry, in children aged 3-19y. Am J Clin Nutr 72, 490-495.

Taylor RW, Keil D, Gold EJ, Williams SM \& Goulding A (1998) Body mass index, waist girth, and waist-to-hip ratio as indices of total and regional adiposity in women: evaluation using receiver operating characteristic curves. Am J Clin Nutr 67, 44-49.

Treuth MS, Hunter GR \& Kekes-Szabo K (1995) Estimating intraabdominal adipose tissue in women by dual energy X-ray absorptiometry. Am J Clin Nutr 62, 527-532.

Vague J, Vague P, Meignen JM, Jubelin J \& Tramoni M (1985) Android and gynoid obesities. Past and present. In Metabolic Complications of Human Obesities, pp. 3-11 [J Vague, P Bjorntorp, B Guy Grand, M Refuffe-Scrive and P Vague, editors]. Amsterdam: Excerpta Medica.

Valdez R, Seidell JC, Ahn YI \& Weiss KM (1993) A new index of abdominal adiposity as an indicator of risk for cardiovascular disease. A cross-population study. Int J Obes Relat Metab Disord 17, $77-82$.

Van Pelt RE, Evans EM, Schechtman KB, Ehsani AA \& Kohrt WM (2002) Contributions of total and regional fat mass to risk for cardiovascular disease in older women. Am J Physiol Endocrinol Metab 282, E1023-E1028.

Vapnik V (1998) Statistical Learning Theory. New York: Wiley.

Vickery SR, Cureton KJ \& Collins MA (1988) Prediction of body density from skinfolds in black and white yong men. Hum Biol 60, $135-149$.

Zamboni M, Armellini F, Harris T, Turcato E, Micciolo R, Bergamo-Andreis IA \& Bosello O (1997) Effects of age on body fat distribution and cardiovascular riskfactors in women. Am J Clin Nutr 66, 111-115. 